\title{
Identification of house price bubbles using user cost in a state space model
}

Hanxiong Zhang hzhang@lincoln.ac.uk

Lincoln Business School, University of Lincoln, Lincoln, LN6 7TS, UK

Robert Hudson robert.hudson@ncl.ac.uk

Hull University Business School, University of Hull, Hull, HU6 7RX, UK

Hugh Metcalf hugh.metcalf@ncl.ac.uk

Newcastle University Business School, University of Newcastle, Newcastle upon Tyne, NE1 4SE, UK

Viktor Manahov viktor.manahov@york.ac.uk

The York Management School, University of York, York, YO10 5GD, UK

\begin{abstract}
This paper studies how much variation in house prices results from non-fundamental factors. We propose a relative valuation approach to quantifying a bubble in housing by incorporating the housing User Cost into a State-Space model. We find UK house prices were under-valued from January 1995 to May 2001 and subsequently moved into a bubble over the period to October 2012. Our results support the bounded rationality hypothesis in the long-run. However, we also find that the irrational and the rational expectation hypotheses can coexist in the short-run when explosive bubbles are driven by price dynamics.

JEL Classification: C51; G02; G12.
\end{abstract}




\section{Introduction}

Conventional wisdom suggests that assuming rational expectations and the rational behaviour of market participants, any asset should be priced based on its fundamental value which is normally defined as the summation of discounted future cash inflows. A persistent and substantial divergence between market price and the fundamental value of an asset is evidence of a bubble. In an efficient market, where the current asset price has fully, instantaneously and correctly reflected all relevant information, there are no bubbles. However, there are a number of papers in the literature suggesting that house prices may contain a bubble element (for example, Case and Shiller (2003) for the US, Black et al. (2006) for the UK and Xiao and Tan (2007) for Hong Kong). From an academic perspective, it is interesting to investigate how much variation in house prices results from bubbles. From a practical perspective, the quantification of bubbles in house prices will make market participants aware of the size of their risk exposure and can help them to detect early signals of the possibility of a financial market crash (Reinhart and Rogoff, 2009). These signals drive investors to respond rationally and adjust house prices toward their fair value. Furthermore, policy-makers can use information about the existence and size of bubbles in order to stabilize the market.

Black et al. (2006) find that intrinsic bubbles, which depend on the Bounded Rationality Hypothesis, have an important role to play in determining actual house prices in the UK over the period from 1973Q4 through 2004Q3 by using a Vector Autoregression (VAR) based timevarying risk present value model. Our paper considers if their result is supported by using a User Cost Framework based State Space model and, in particular, whether the bounded rationality hypothesis describes the UK housing market in the short-run. 
Regarding the study of asset price bubbles, the literature can be broadly classified into two groups, namely, indirect bubble tests and direct bubble tests. The indirect bubble tests attempt to overcome the econometric limitations of standard tests by implementing sophisticated cointegration and unit root tests to price-dividend or analogous relationships (Al-Anaswah and Wilfling, 2011). The indirect bubble tests literature includes Diba and Grossman (1988), Evans (1991) and McMillan (2007) and Phillips et al. (2011) for the stock market, Phillips and Yu (2011) for US house prices and Kivedal (2013) for UK house prices. One essential limitation of the indirect bubble tests is that they cannot generate a time series of the bubble component. By contrast, the direct bubble tests explicitly identify the deviation of asset prices from the determined fundamental values, and use the discrepancies to generate a bubble time series. The direct bubble tests includes Himmelberg et al. (2005) for the US, Black et al. (2006) for the UK and Xiao and Tan (2007) for Hong Kong. Given the fundamental value is typically inferred, rather than directly observed, the estimation of bubbles varies with respect to the selection of datasets and models. As our paper aims to extract a bubble time series and investigate the path of the bubble, the methodology of this paper follows the direct bubble tests.

Although many papers in the literature agree about the presence of bubbles in financial markets, there are controversies about the features of a bubble. Under the Rational Expectation Hypothesis, Abreu and Brunnermeier (2003) argue that an asset bubble can persist despite the presence of rational arbitrageurs. Rational bubbles occur when asset prices continue to rise because people believe that they will be able to sell the overpriced asset at a higher price in the future (Black et al., 2006, Diba and Grossman, 1988). Therefore, rational bubbles are associated with explosive conditional expectations. Housing literature supporting the rational expectation hypothesis includes Phillips and Yu (2011) for the US and Xiao and Tan (2007) for Hong Kong. 
Under the Bounded Rationality Expectation Hypothesis, Froot and Obstfeld (1991) suggest intrinsic bubbles or bounded rational bubbles do not continuously diverge but periodically revert toward their fundamental value and are statistically correlated with fundamental variables. The bounded rationality bubble captures the idea that asset prices overreact to relevant information about fundamentals. Empirical literature supporting the bounded rationality expectation hypothesis includes Black et al. (2006) for the UK. Under the Irrational Expectation Hypothesis, irrational bubbles, also named momentum bubbles, are independent of fundamental values (Black et al., 2006). An irrational bubble results from people being driven by price alone, whereby people buy after price increases and sell after price decrease. Empirical literature supporting the irrational expectation hypothesis includes Case and Shiller (2003), Kivedal (2013) for the US, Brooks et al. (2001) and McMillan and Speight (2010) for the UK.

The majority of the empirical literature has one major drawback. It uses statistical tests to assess the rationality of house price bubbles over the whole of some predefined period. This means that the rationality of house prices is regarded as a static condition. However, it is reasonable to anticipate that the rationality of house prices may evolve over time due to varying underlying market factors, such as regulatory, technological and expectation changes.

We contribute to the literature in two respects. Firstly, we propose a relative valuation approach to quantifying a bubble in housing by incorporating the present value of housing User Cost into a State Space Model. The idea is to spot bubbles as they emerge, not just after they have collapsed. This approach bases the estimation of fundamental housing value on the user cost framework which takes mortgage rates, taxes, rent levels, expected capital gain and people's risk premium into account in a comprehensive assessment of all relevant factors. Subsequently, the unobservable bubble time series is estimated by taking advantages of a Kalman filter within a 
state space model. Our approach is a relative valuation approach which contrasts to the discounted cash flow valuation approach used in many previous studies such as that of Black et al. (2006) and Xiao and Tan (2007). The key advantage of a relative valuation approach, especially when contrasted with the present value approach, is that house purchase prices are not necessarily the summation of discounted future values. Moreover, a relative valuation approach is much more likely to reflect people's psychology and expectations than a discounted cash flow valuation approach in the short-run, since it is an attempt to measure relative and not intrinsic value (Damodaran, 2002, p.949). The present value model also has the disadvantage of being extremely sensitive to the quality of inputs, such as the estimate of the discount rate.

Secondly, our results favour the bounded rational bubbles in the long-run. However, there is also evidence to support the irrational and rational bubbles can coexist in the short-run when explosive bubbles are driven by price dynamics. Furthermore, the rationality of house price bubbles evolves over time. Our results suggest that people’s expectations and economic behaviour might be biased due to cognitive and psychological limitations which, in turn, indicate people might act in an irrational way in the short-run. However, people learn from their mistakes and attempt to satisfice by acting as rationally as possible in the long-run.

The remainder of the paper is structured as follows. Section II outlines the methodology of using the User Cost Framework within a State-Space Model. Section III gives a description of the data. Section IV reports the empirical results and discussion. Section V concludes the paper.

\section{Empirical Methodology}

Given that house price $p_{t}$ is a combination of fundamental element $p_{t}^{f}$ (which is a function of the fundamental price-rent ratio $p r_{t}^{f}$ and the rental $r_{t}$ ), non-fundamental or bubble element $b_{t}$ and 
model misspecification error $\varepsilon_{t}$ (Wu, 1997, Xiao and Tan, 2007), see equation (1), we propose an approach to quantify housing bubbles using a combination of market indicator and existing econometric models, namely a User Cost framework within a State Space Model.

$p_{t}=f\left(p_{t}^{f}, b_{t}, \varepsilon_{t}\right)=f\left(p r_{t}^{f}, r_{t}, b_{t}, \varepsilon_{t}\right)=\beta_{1} p r_{t}^{f}+\beta_{2} r_{t}+\beta_{3} b_{t}+\varepsilon_{t}$

Throughout the paper, the lower case letters represent the natural log of the underlying variables. $\beta_{1}, \beta_{2}$ and $\beta_{3}$ are the relevant elasticities. $\beta_{1}=\beta_{2}=\beta_{3}=1$ would be the special case of equilibrium. In equation (1), the fundamental house price-rent ratio $p r_{t}^{f}$ and the bubble $b_{t}$ are not directly observable. As the first step, this paper uses the user cost framework to estimate the fundamental house price-rent ratio $p r_{t}^{f}$. As a second step it uses a linear state space model to estimate the unobservable bubble time series $b_{t}$.

The user cost step

The user cost of ownership and the implied fundamental price-rent ratio is the most complete framework to assess when home prices are misaligned (Finicelli, 2007) out of those in the simple market indicators.

The user cost framework suggests that people should be indifferent between renting and purchasing, given the same cost and housing attributes (Himmelberg et al., 2005). The user cost of holding a house, in percentage terms, is the sum of six components, as shown in equation (2).

$U C_{t}=R_{t}^{m}+P T_{t}+M C_{t}+R P_{t}-M T_{t}\left(R_{t}^{m}+P T_{t}\right)-C G_{t+1}$

$R_{t}^{m}$ is the mortgage rate, $P T_{t}$ is the property tax rate, $M C_{t}$ is the depreciation rate of the property or its maintenance cost, $R P_{t}$ is the risk premium reflecting the larger uncertainty of purchasing relative to renting. $M T_{t}$ is the marginal tax rate for the house buyer. As nominal 
mortgage payments and property taxes are tax deductible in many tax regimes, they often provide an offsetting benefit to the home owner. $C G_{t+1}$ is the expected capital gain from owning the house for one year.

In the equilibrium condition, the annual cost of owning a house should equal the average corresponding market rent, see equation (3):

$R_{t}=P_{t}^{f} \times U C_{t}$

$R_{t}$ is actual market rent, $P_{t}^{f}$ is the fundamental housing price. Equation (3) implies the fundamental house price-rent ratio is the inverse of user cost, say $P_{t}^{f} / R_{t}=1 / U C_{t}$.

As a second step, this paper incorporates the user cost based fundamental house price-rent ratio into the state space model.

The state space model step

A state space model consists of two equations: a measurement equation and a state equation. The measurement equation illustrates the relation between observed variables and unobserved state variables. The state equation illustrates the dynamics of the unobserved state variables, normally in the form of a $\operatorname{VAR}(1)$ in the state vector.

Once a model has been expressed in a state space form, some important algorithms can be applied, the Kalman filter being central. The Kalman filter is a recursive procedure for estimating the optimal estimator of the state vector at time $t$, based on the information available at time $t$. The Kalman filter assures the estimation of the state vector is continually updated as new information becomes available. When the disturbance and the initial state vector follow a normal 
distribution, the likelihood function can be accurately calculated via what is known as the ‘prediction error decomposition’ (Hamilton, 1994, chapter 13).

Based on the existing literature (Wu, 1997, Xiao and Tan, 2007) and equation (1), this paper defines the following state space model.

Measurement equation:

$p_{t}=c_{1} p r_{t}^{f}+c_{2} r_{t}+b_{t}+\epsilon_{1}$

$p_{t}$ is the $\log$ house price, $p r_{t}^{f}$ is the $\log$ fundamental price-rent ratio which is calculated as $\log \left(1 / U C_{t}\right), r_{t}$ is the log rent, and $b_{t}$ is the level of any bubble in log scale.

State equation:

$b_{t}=c_{3} b_{t-1}+\epsilon_{2}$

Where, $c_{1}, c_{2}$ and $c_{3}$ are the relevant elasticities. $\epsilon_{1}$ and $\epsilon_{2}$ are the error terms for the measurement and state equations. $\epsilon_{1} \sim N I D\left(0, \sigma_{\epsilon_{1}}^{2}\right), \epsilon_{2} \sim N I D\left(0, \sigma_{\epsilon_{2}}^{2}\right), E\left(\epsilon_{1}, \epsilon_{2}^{\prime}\right)=0, E\left(\epsilon_{1}, b_{0}^{\prime}\right)=$ 0 and $E\left(\epsilon_{2}, b_{0}^{\prime}\right)=0 . b_{0}^{\prime}$ is the initial state vector. $\sigma_{\epsilon_{1}}^{2}$ and $\sigma_{\epsilon_{2}}^{2}$ are the variances of the error terms for the measurement and state equations. To guarantee nonnegative variance estimates, variances are defined as exponential functions of the $\epsilon_{1}$ and $\epsilon_{2}$. When $c_{3}>1$, the deviation from fundamental value $b_{t}$ has an explosive path and this would support the rational bubble hypothesis (Phillips et al., 2011).

The state space model has five unknown parameters, $\Psi=\left(c_{1}, c_{2}, c_{3}, \sigma_{\epsilon_{2}}^{2}, \sigma_{\epsilon_{2}}^{2}\right)^{\prime} . \Psi$ are termed as hyperparameters and are estimated by Maximum Likelihood Estimation (MLE) using the Marquardt algorithm, in this paper. 
Basically, one cannot determine the scale of the state variable, putting the coefficient of state variable $b_{t}$ equals to 1 is one way to achieve scaling. It is not possible to both estimate a coefficient for $b_{t}$ and the variance of $\epsilon_{2}$ because they play effectively the same role of scaling the unobserved stationary component $b_{t}$.

There are no constants in equation (4) and equation (5), given that the expected value of housing will be zero when the fundamental value and bubble are both zero. The rationale for using an AR(1) for the bubble process is based on the assumption that people will naively extrapolate the most recent price deviation level into the next period (Wu, 1997). The state space model step simplifies the model building process relative to Wu (1997) and Black et al. (2006) while maintaining the advantages of a state space model. Unlike regular time series regressions, the stationarity of a time series is not required in a state space model (Commandeur and Koopman, 2007, p.134).

Both Wu (1997) and Xiao and Tan (2007) presume the bubble is rational and use the first log differenced variables in their measurement equations, therefore, they estimate changes in bubble size rather than the level of bubble. Consequently, they are unable to make an absolute statement about the proportion of bubble in each price index (Xiao and Tan, 2007). Furthermore, Xiao and Tan (2007) treat the model specification error as the state variable and then estimate the house price bubble as the residual of the measurement equation.

Theoretically, any factor that is not in the pricing model will contribute to the specification errors of that model. Thus the bubble component is a part of the specification error. If the goal of the model is to estimate a price bubble, one needs to decompose the error term into two parts, namely, the bubble component and the remaining non-bubble specification error component 
(Wu, 1997, Xiao and Tan, 2007). Unfortunately, from a purely statistical point of view, there is no way to do this. Therefore, it is necessary to make an assumption, based on economic intuition, about the distribution of the bubble component and non-bubble specification error component. In contrast to Xiao and Tan (2007), we treat the bubble as a state variable which follows an AR(1) process. In addition, the non bubble specification error of a well-defined linear state space model should be an i.i.d. process (Commandeur and Koopman, 2007, p.134).

The state space model with user cost framework suffers from some potential drawbacks. For instance, the model assumes the bubble follows a linear Gaussian process. If the natural log of bubble is a non-linear, non-Gaussian process, the particle filter instead of the Kalman filter appears more suitable (Arulampalam et al., 2002). This refinement is left for future research.

\section{Data Description}

The data included in this study are the UK Halifax House Price Index (HPI), a House Rent Index (HRI) which is derived from the UK Retail Price Index component of rents for housing, and the composite mortgage rate of banks and building societies from the Bank of England. The monthly UK time series data are all collected from DataStream with a time span from January 1995 to October 2013. The start and end dates are determined by the availability of data for the monthly composite mortgage rate. This paper sets $H P I=H R I=100$ in November 2003. Because the annual capital gain at any point is calculated as the price appreciation over the next 12 months, we estimate the equations from January 1995 to October 2012, except where specifically mentioned.

The Halifax HPI is the UK's longest running monthly house price series with data covering the whole country. The Halifax HPI is calculated using hedonic regression, using mortgage 
completion data from the Halifax which is the largest UK mortgage provider. Black et al. (2006) use the Nationwide HPI covers quarterly periods from 1973Q4 through 2004Q3 which is also calculated using hedonic regression, but using data from the Nationwide Building Society’s mortgage lending. Our dataset is comparable to Black et al. (2006) but extends the study to a recent sample and provides a greater number of observations, which will enhance the power of any statistical tests employed.

Black et al. (2006) deflate all the nominal variables by the Retail Price Index (all items) thus providing prices in real terms. In this paper, however, all the variables are in nominal terms for two reasons. Firstly, 'there is a great deal of confusion about the role of inflation expectations in the demand for housing' (Schwab, 1982). Some argue that the nominal interest rate and inflation are major determinants of the demand for housing (Poterba, 1984). Others suggest inflation expectations are independent of the demand for housing; and that only deflated variables are relevant (Arcelus and Meltzer, 1973). Schwab (1982) suggests that the truth lies somewhere between these two extremes. Therefore, it is interesting to study whether the linkages between house prices and its determinants can be replicated in nominal terms. Secondly, the bulk of people when deciding between owning and renting tend to compare the cost of holding a home and renting a home per year in nominal instead of real terms (Brunnermeier and Julliard, 2008). Akerlof and Shiller (2010, p41) suggest people often fail to exclude the effect of inflation on their investments.

Insert Fig. 1 Here

Fig. 1 plots the House Price Index against the House Rent Index in natural log scale. Given the paper uses index data based at 100 in November 2003 to proxy house price and rent, it is not surprising to see the figure of House Rent Index is relatively close to the figure of the House 
Price Index, even when house prices are significantly overvalued. Fig. 1 suggests that the UK house prices dramatically boomed from January 1995 to June 2007 and subsequently moved into a recession over the period to October 2012. By contrast, UK rentals slowly but steadily increased from January 1995 to October 2012. Over the full sample the correlation between the two variables is 0.91, while for the sub-period November 2003 through October 2012, the correlation coefficient is almost 0 which implies that house prices could be temporally independent of rentals.

Regarding the calculation of user cost, we follow the standard in the user cost literature in presuming that the maintenance and deprecation rate $M C_{t}=2 \%$ per year (Finicelli, 2007, Girouard et al., 2006, Himmelberg et al., 2005). In accordance with the UK Mortgage Interest Relief at Source (MIRAS) scheme, over some historic periods, a borrower has paid the lender the interest less the tax relief. The rate of relief was 20\% for 1994-1995, from 1995-96 to 1997-98 it was $15 \%$ and for $1998-99$ and $1999-2000$ it was $10 \%$. The relief on mortgage interest repayments was removed on 6 April 2000. Accordingly we set the UK marginal tax rate $M T_{t}=20 \%$ from April 1994 to March 1995, $M T_{t}=15 \%$ from April 1995 to March 1998, $M T_{t}=10 \%$ from April 1998 to March 2000, and $M T_{t}=0$ thereafter. We exclude property tax and set $P T_{t}=0$ for two reasons. Firstly, property tax payment is not deductible from income tax under the UK tax system. Secondly, in the UK, the tenant rather than the landlord is responsible for paying the property tax. As property tax is usually not included in the rent, property tax should also be removed from the user cost.

In the literature, the expected capital gain $C G_{t}$ is often proxied by the past $n$-period moving average of the Consumer Price Index (CPI) and/or the forward looking long-run CPI (Finicelli, 2007, Himmelberg et al., 2005). However, there are several issues with these proxies. Initially, in 
the UK, the calculation of CPI does not consider house prices due to houses being regarded as investment goods rather than consumption goods (Gooding, 2013). Secondly, using past $n$-period moving averages to proxy expected capital gains imposes a very naïve and restrictive view of the way individuals form their expectations.

Unlike previous papers in the literature, this paper uses the ex post realized annual house price return to proxy the ex ante expected annual capital gain, $C G_{t+1}$.

$C G_{t+1}=\frac{P_{t+1}-P_{t}}{P_{t}}$

The rationale is that if people are rational when forming their capital gain expectations, the expectation error should be independent and normally distributed with a mean of zero on average over time. An approach incorporating pure rational expectation is difficult to implement in reality, however, it is reasonable to estimate the historical equilibrium house prices from an $e x$ post rational perspective. The unbiased annual expected capital gain at any point is the price appreciation over the next year so we eliminate problems of biased expectations by construction. The unbiased expected capital gain also captures the effect of many unobservable fundamental factors, such as supply restrictions and regulations.

In line with the rationale used for the expected capital gain $C G_{t+1}$, the risk premium of owning a house relative to renting $R P_{t}$, is calculated as the ex post annual house price return minus ex post annual rental changes.

$R P_{t}=C G_{t+1}-\frac{R_{t+1}-R_{t}}{R_{t}}=\frac{P_{t+1}-P_{t}}{P_{t}}-\frac{R_{t+1}-R_{t}}{R_{t}}$

McCulley (2008) argues that liquidity is not measured properly by the traditional monetary aggregate, but by people's state of mind, in particular their 'appetite for risk'. Therefore, the 
dynamic risk premium $R P_{t}$ would capture market liquidity. However, this method is redundant when estimating the perfect capital gain and risk premium beyond the end period of the sample data, as it assumes investors are ex post rational.

Fig. 2 plots the fundamental price-rent ratio $P_{t}^{f} / R_{t}$, which is the inverse of the user cost time series. The fundamental house price-rent ratio ranges from 13 to 40.66 with a mean of 20.8 and standard deviation of 6.17. In Fig. 2 the graph shows a dramatic fall right at the start of 1995 because of the cut in the marginal tax rate and the sharp increase of the risk premium and expected capital gain. Driven by the low mortgage rates and high expected capital gain, the ratio rebounded sharply from the local bottom of 15 in May 2002 to a peak of 40.66 by December 2011. The implied fundamental price for investors to buy a house on average is approximately 20.8 times the market rent between 1995 and 2013, ceteris paribus.

Insert Fig. 2 Here

Table 1 presents the preliminary statistics about the house price (HPI), rent (HRI) and fundamental price-rent ratio using natural logs. An augmented Dickey-Fuller (ADF) unit root test shows that the three variables are non-stationary in levels at the conventional significance levels. However, the three variables are all stationary at the $5 \%$ significance level after taking first differences. The Johansen maximum eigenvalue test shows that house price $p_{t}$, rent $r_{t}$ and the fundamental price-rent ratio $p r_{t}$ are cointegrated at the $5 \%$ significance level, meaning that house prices have a long-run stable relationship with the fundamental variables. Thereby, speculative or market shocks may drive house prices away from market fundamentals in the short-run but fundamentals will eventually drive the house prices to converge to the equilibrium in the long-run. 


\section{Insert Table 1 Here}

\section{Empirical Results and Discussion}

\section{The estimation of bubbles}

Table 2 displays the empirical results of the state space model, equations (4) through (5). All the three coefficients $c_{1}, c_{2}$ and $c_{3}$ are statistically significant different from 0 at the $1 \%$ level. According to the authors' calculation, the statistical significance for the hypothesis $c_{1}=1$ can be rejected at the $1 \%$ significance level but the hypothesis $c_{2}=1$ cannot be rejected at the conventional significance level. Therefore, it will be somewhat problematic to set $c_{1}=c_{2}=1$ in equation (4). An ADF unit root test shows that the deviation $b_{t}$ is nonstationary in levels but stationary after first differencing at the $1 \%$ significance levels. In Table 2 , the diagnostic tests concerning the residuals of the State Space model suggest that the residuals are independent, homoscedastic and normally distributed. Therefore, the assumptions for the state space model are fulfilled (Commandeur and Koopman, 2007, p.90).

Insert Table 2 Here

Fig. 3 plots the deviations from fundamental value $b_{t}$. When the price-deviation is above 0 this indicates the price is above its fundamental value and vice versa. From Fig. 3, the UK house prices are undervalued from January 1995 to May 2001 and subsequently move into being overvalued over the period to October 2012. The deviations from fundamental value $b_{t}$ range from -22\% in January 1995 to 64\% in August 2007 which is indeed a quite substantial range. Hit by the Subprime Crisis, the deviation $b_{t}$ sharply decreased to 33\% by April 2009; recovered to 39\% in April 2010; and decreased to 27\% by October 2012. Given that the price deviations from 
fundamental value $b_{t}$ are substantial and persistent, the figures indicate that $b_{t}$ reflects a bubble process.

The findings of Fig. 3 are broadly consistent with the existing UK housing literature. However, our approach is much more comprehensive and reliable than the simple price-income ratio and price-rent ratio as it takes mortgage rates, taxes, rent levels, expected capital gain and people's risk premium into account in a comprehensive assessment of all relevant factors (Girouard et al., 2006, Himmelberg et al., 2005). Compare to the findings of the price-income ratio and price-rent ratio in Girouard et al. (2006), the size of deviations from fundamental $b_{t}$ in Fig. 3 are much more modest. Furthermore, our approach simplifies the model building process while maintaining the advantages of a state space model and shows compatible empirical findings with those of Black et al. (2006).

\section{Insert Fig. 3 Here}

Following Phillips et al. (2011), the recursive ADF statistics for the log house price $p_{t}$ and log rent $r_{t}$ are plotted in Fig. 4 to investigate whether the bubbles $b_{t}$ are explosive rational bubbles or not. For each variable, we estimate the following ADF test specification:

$x_{t}=\alpha+\delta x_{t-1}+\sum_{i=1}^{I} \beta_{i} \Delta x_{t-i}+\varepsilon_{t}, \quad \varepsilon_{t} \sim N I D\left(0, \sigma^{2}\right)$

The null hypothesis is $H_{0}: \delta=1$ and the right-tailed alternative hypothesis is $H_{1}: \delta>1$. In forward recursive regressions, equation (8) is estimated repeatedly, using subsets of the sample data incremented by one observation at each pass. The first sample period is from January 1995 to December 1997. The optimal lag length is determined using the top-down procedure as in Phillips et al. (2011). The more the ADF statistics exceed the right-tailed ADF critical value, the 
stronger the support for explosive behavior. If house prices are more explosive than rentals then it can be concluded that rational bubbles are present (Phillips et al., 2011).

It is evident from Fig. 4 that the rental $r_{t}$ is always non-explosive. However, the house price $p_{t}$ is explosive between October 1999 and April 2008, supporting the evidence of rational bubbles in the UK house prices prior to the Subprime Crisis. The ADF statistics for the bubble $b_{t}$ is highly consistent with those of house price. The presence of rational bubbles suggests some nonfundamental factors such as peoples' biased forward looking expectations, played an important role in driving UK house prices from October 1999 to April 2008. The findings of Fig. 4 are roughly consistent with Phillips and Yu (2011) for US house prices but contrast to Black et al. (2006) for the UK.

Insert Fig. 4 Here

What drives house price bubbles to evolve over time?

Froot and Obstfeld (1991) suggest that the deviations of prices from fundamental values $b_{t}$ can be interpreted by nonlinear deterministic functions of the fundamentals of asset value alone. When this is true, then, the deviations of prices from fundamental values are intrinsic bubbles. Intrinsic bubbles depend on the hypothesis of bounded rationality and self-fulfilling expectations. Intrinsic bubbles do not continuously diverge but periodically revert toward their fundamental value. The bounded rationality hypothesis argues that people form expectations and make decisions to help them satisfice rather than make theoretically optimal decisions. Therefore, people make mistakes in the short-run, but learn from their mistakes in the long-run. The bounded rationality hypothesis essentially implies that there is cointegration or long-run equilibrium between fundamental factors and house price bubbles. Moreover, intrinsic bubbles 
will be more highly correlated with fundamental factors than with prices themselves (Black et al., 2006), meaning that the dominant driving force is fundamentals rather than price dynamics.

When the bubbles are not significantly related to fundamental variables but to lagged price dynamics, then, the bubbles are momentum bubbles and reflect the backward looking irrational expectation hypothesis. The irrational expectation hypothesis suggests that people buy after price increases and sell after price falls (Case and Shiller, 2003, Shiller, 1990). Alhashimi and Dwyer (2004) suggest that people buy homes infrequently, with a tiny proportion of households active at any one time. Thus changes in the behaviour of a few people could, regionally at least, have substantial influences on aggregate house prices. Kogan et al. (2006) demonstrate that long-run survival and asset price impact are two independent concepts. Irrational people can survive and even dominate rational people at least temporarily.

In an attempt to distinguish between the competing bounded rationality and irrationality hypotheses, Table 3 exhibits the Johansen cointegration tests for bubbles and the relevant variables. Cointegration is superior to correlation in terms of revealing long-run dynamic causal relationships between variables (Hamilton, 1994, chapter 19). From Table 3, bubbles $b_{t}$ and house prices $p_{t}$ are not cointegrated at the conventional significance levels. However, bubbles $b_{t}$, fundamental price-rent ratios $p r_{t}^{f}$ and rents $r_{t}$ are cointegrated at the $5 \%$ significance level. Table 3 implies that there is no long-run equilibrium between house price bubbles and price dynamics. However, there exists a stable dynamic relationship between bubbles and fundamentals in the long-run. Thereby, Table 3 supports the bounded rationality expectation hypothesis in the long-run, which is consistent with Black et al. (2006).

Insert Table 3 Here 
In order to highlight the short-run dynamic characteristics of house price bubbles given the longrun cointegration (equilibrium) relationship, we run an Error Correction Model (ECM) as shown in equation (9).

$\Delta b_{t}=\alpha+\beta_{1} \Delta r_{t}+\beta_{2} \Delta p r_{t}^{f}+\beta_{3}$ cointeq $_{t-1}+\varepsilon_{t}$

Where $\Delta b_{t}$ is the change in house price bubbles, $\Delta r_{t}$ is the change in rent, $\Delta p r_{t}^{f}$ is the change in the fundamental price-rent ratio, cointe $q_{t-1}$ is the first lagged cointegration term generated for the bubble $b_{t}$, the fundamental price-rent ratio $p r_{t}^{f}$ and the House Rent Index $r_{t}$ over the full sample. In equation (9), $\beta_{1}$ and $\beta_{2}$ capture the short-run effects of fundamental factors on house price bubbles. $\beta_{3}$ measures the speed of error correction at which bubbles adjust to the equilibrium state after an overreaction to fundamentals. From Table 4, the coefficient on the changes in rent $\beta_{1}$ is statistically significant at a $10 \%$ significance level. Thus the change in rent $\Delta r_{t}$ has statistically weak short-run effects on the changes in house price bubbles $\Delta b_{t}$, ceteris paribus. The coefficient for the changes in fundamental price-rent ratio $\beta_{2}$ is statistically insignificant, which challenges the hypothesis that fundamental price-rent ratio $p r_{t}^{f}$ has significant short-run effects on changes in bubbles. $\beta_{3}$ is statistically significant and negative, suggesting that deviation from equilibrium are corrected at the rate of about $0.76 \%$ per month. As a comparison, Table 4 also shows the results of regressing the changes in bubbles $\Delta b_{t}$ against the lagged changes in house prices $\Delta p_{t-1}$, see equation (10).

$\Delta b_{t}=\alpha+\beta \Delta p_{t-1}+\varepsilon_{t}$

Insert Table 4 Here 
The coefficient on the lagged changes in house prices is 0.3046 and statistically significant at the $1 \%$ significance level, suggesting that $1 \%$ changes in house prices could drive subsequent house prices bubbles changes by $0.3 \%$ in the short-run. Thus the changes in bubbles are highly correlated with price dynamics rather than fundamentals, suggesting that the dominant driving force in bubbles is people's overreaction to house price movements rather than fundamentals. Thereby, Table 4 seems to support the irrational expectation hypothesis in the short-run which appears to contrast with Black et al. (2006).

We check the robustness of the irrational expectation hypothesis in the short-run by running a recursive OLS regression of equation (10). The first sample is from January 1995 to December 1997. It is evident from Fig. 5 that the coefficients for the lagged changes in house prices are statistically significant between May 2003 and October 2012 with values ranging from 0.21 to 0.38, which are consistent with Table 4 and supports the irrational expectation hypothesis in the short-run.

In contrast to the majority of housing literature, our findings so far suggest that the rationality of the house prices may evolve over time. In the short-run, non-fundamental factors, in particular, people's expectations of large price increases might have an amplification impact on demand if people overact to fundamentals and believe that house price increases will continue. This feedback process drives house prices to go up even in an explosive way for a while. Rational and irrational bubbles could coexists (e.g. in the period from May 2003 to April 2008 in the UK), when the explosion of bubbles are driven by price dynamics. When people perceive that prices cannot go up, prices could then fall as a result of diminished demand: the bubble bursts (Case and Shiller, 2003). In the long-run, the coordination of rational people drives house prices to converge to their fundamentals. 
Insert Fig. 5 Here

\section{Conclusions}

This paper studies how much variation in house prices results from non-fundamental factors by quantifying the size of housing bubbles. The paper contributes to the literature both methodologically and empirically. Using a user cost framework within a state space model has clear methodological advantages. As a first step, the fundamental house price-rent ratio is calculated using the user cost framework which has the benefit compared to many prior papers of incorporating all the relevant variables affecting house price fundamentals. In the second step, the method can advantageously estimate the level of any bubble by incorporating the fundamental price-rent ratio into a state space model by taking advantage of a Kalman filter.

Our empirical results indicate that UK house prices were undervalued from January 1995 to May 2001 and subsequently moved into a bubble over the period to October 2012. As a proportion, of house price the bubble ranged from $-22 \%$ to $64 \%$ in log scale, which is indeed a quite substantial range. The magnitude of this range indicates that any modelling of house prices without the consideration of a bubble element, or the non-fundamental components, will be somewhat problematic.

From a theoretical viewpoint our results favour the bounded rationality hypothesis in the longrun. However, the results provide a strong evidence to support the coexistence of rational and the irrational expectation hypotheses in the short-run. Furthermore, in contrast to the majority of the existing literature, the results show that the rationality of house price bubbles evolves over time. Our empirical findings suggest that people’s expectations and economic behaviours might be biased due to cognitive and psychology limitations which, in turn, indicate the market might be 
inefficient at least temporarily. However, people learn from their mistakes and attempt to satisfice by acting as rationally as possible in the long-run.

From a practical perspective, the quantification of bubbles in house prices can make market participants aware of the size of their risk exposure and can help them to detect early signals of the possibility of a financial market crash. For financial institutions, periodically assessing the state of the housing market, rational diversification and timely rebalancing of portfolios may help them prevent losses similar to those suffered in the Subprime Crisis. Signals regarding a bubble may drive investors to respond rationally and adjust house prices toward their fair value.

Furthermore, policy-makers can use information about the existence and size of bubbles in order set policies to stabilize the market.

There are several avenues for future research in this area. The method can be applied to other markets and time periods and compared to other approaches. Detailed consideration of the various components of the user cost can also give a guide to the relative influences of different factors on house prices and the size of any bubble component. This understanding is potentially very useful for policy formation. 


\section{References}

ABREU, D. \& BRUNNERMEIER, M. K. 2003. Bubbles and crashes. Econometrica, 71, 173204.

AHKING, F. W. 2002. Model mis-specification and Johansen's co-integration analysis: an application to the US money demand. Journal of Macroeconomics, 24, 51-66.

AKERLOF, G. A. \& SHILlER, R. J. 2010. Animal Spirits: How Human Psychology Drives the Economy, and Why It Matters for Global Capitalism (New in Paper), Princeton University Press.

AL-ANASWAH, N. \& WILFLING, B. 2011. Identification of speculative bubbles using statespace models with Markov-switching. Journal of Banking and Finance, 35, 1073-1086.

ALHASHIMI, H. \& DWYER, W. 2004. Is there such an entity as a housing market? 10th Annual Pacific Rim Real Estate Conference. Bangkok.

ARCELUS, F. \& MELTZER, A. H. 1973. The markets for housing and housing services. Journal of Money, Credit and Banking, 5, 78-99.

ARULAMPALAM, M. S., MASKELL, S., GORDON, N. \& CLAPP, T. 2002. A tutorial on Particle Filters for online nonlinear/non-Gaussian Bayesian tracking. Signal Processing, IEEE Transaction, 50, 174 - 188. 
BARKOULAS, J. \& BAUM, C. F. 1997. A re-examination of the fragility of evidence from cointegration-based tests of foreign exchange market efficiency. Applied Financial Economics, 7, 635-643.

BLACK, A., FRASER, P. \& HOESLI, M. 2006. House prices, fundamentals and bubbles. Journal of Business Finance and Accounting, 33, 1535-1555.

BRUNNERMEIER, M. K. \& JULLIARD, C. 2008. Money illusion and housing frenzies. Review of Financial Studies, 21, 135-180.

CASE, K. E. \& SHILLER, R. J. 2003. Is there a bubble in the housing market? Brookings Papers on Economic Activity, 34, 299-362.

COMMANDEUR, J. J. F. \& KOOPMAN, S. J. 2007. An Introduction to State Space Time Series Analysis, Oxford, Oxford University Press.

DAMODARAN, A. 2002. Investment Valuation: Tools and Techniques for Determining the Value of Any Asset, Wiley.

DIBA, B. T. \& GROSSMAN, H. I. 1988. Explosive rational bubbles in stock prices? The American Economic Review, 78, 520-530.

ENDERS, W. 2010. Applied Econometric Time-Series, New York, John Wiley and Sons. 
EVANS, G. W. 1991. Pitfalls in testing for explosive bubbles in asset prices. The American Economic Review, 81, 922-930.

FINICELLI, A. 2007. House Price Developments and Fundamentals in the United States.

FROOT, K. A. \& OBSTFELD, M. 1991. Intrinsic bubbles: The case of stock prices. The American Economic Review, 81, 1189-1214.

GIROUARD, N., KENNEDY, M., VAN DEN NOORD, P. \& ANDRÉ, C. 2006. Recent house price developments: The role of fundamentals. OECD Economics Department Working Papers No. 475.

GOODING, P. 2013. Consumer Prices Index and Retail Prices Index: The 2013 Basket of Goods and Services. Office for National Statistics.

HAMILTON, J. D. A. 1994. The Time Series Analysis, Princeton University Press.

HIMMELBERG, C., MAYER, C. \& SINAI, T. 2005. Assessing high house prices: Bubbles, fundamentals and misperceptions. Journal of Economic Perspectives, 19, 67-92.

KIVEDAL, B. K. 2013. Testing for rational bubbles in the US housing market. Journal of Macroeconomics, 38, Part B, 369-381.

KOGAN, L., ROSS, S. A., WANG, J. \& WESTERFIELD, M. M. 2006. The price impact and survival of irrational traders. The Journal of Finance, 61, 195-229. 
MCCULLEY, P. A. 2008. The liquidity conundrum. CFA Institute Conference Proceedings Quarterly, 25, 1-4.

MCMILLAN, D. G. 2007. Bubbles in the dividend-price ratio? Evidence from an asymmetric exponential smooth-transition model. Journal of Banking and Finance, 31, 787-804.

MCMILLAN, D. G. \& SPEIGHT, A. 2010. Bubbles in UK house prices: Evidence from ESTR models. International Review of Applied Economics, 24, 437-452.

PHILLIPS, P. C. B., WU, Y. \& YU, J. 2011. Explosive behavior in the 1990s NASDAQ: When did exuberance escalate asset values? International Economic Review, 52, 201-226.

PHILLIPS, P. C. B. \& YU, J. 2011. Dating the timeline of financial bubbles during the subprime crisis. Quantitative Economics, 2, 455-491.

POTERBA, J. M. 1984. Tax subsidies to owner-occupied housing: An asset-market approach. The Quarterly Journal of Economics, 99, 729-752.

REINHART, C. M. \& ROGOFF, K. S. 2009. The aftermath of financial crises. American Economic Review, 99, 466-72.

SCHWAB, R. M. 1982. Inflation expectations and the demand for housing. The American Economic Review, 72, 143-153. 
SHILLER, R. J. 1990. Market volatility and investor behavior. The American Economic Review, 80, 58-62.

WU, Y. 1997. Rational bubbles in the stock market: Accounting for the US stock-price volatility. Economic Inquiry, 35, 309-319.

XIAO, Q. \& TAN, G. K. R. 2007. Signal extraction with Kalman filter: A study of the Hong Kong property price bubbles. Urban Studies, 44, 865-888. 


\section{TABLES}

\section{Table 1 Descriptive Statistics}

\begin{tabular}{lccc}
\hline & House Price Index $\boldsymbol{p}_{\boldsymbol{t}}$ & House Rent Index $\boldsymbol{r}_{\boldsymbol{t}}$ & F. Price/Rent Ratio $\boldsymbol{p r}_{\boldsymbol{t}}^{\boldsymbol{f}}$ \\
\hline No. of Observations & 214 & 214 & 214 \\
Mean & 4.4274 & 4.6110 & 2.9989 \\
Median & 4.6054 & 4.6054 & 2.9433 \\
Maximum & 4.9631 & 4.8551 & 3.7053 \\
Minimum & 3.7645 & 4.3142 & 2.5657 \\
Standard Deviation & 0.4057 & 0.1448 & 0.2571 \\
ADF test & -0.0456 & -0.9607 & -1.8733 \\
Johansen Test & & $22.436^{* *}$ & \\
& & $(21.132)$ & \\
\hline
\end{tabular}

Notes: F.Price/Rent ratio $p r_{t}^{f}$ is the fundamental price-rent ratio. For Augmented Dickey-Fuller

(ADF) tests, the values are statistics. The Johansen maximum eigenvalue test tests the null

hypothesis that there is no cointegration against the alternative that there is at most one

cointegrating vector. The figure in parenthesis under the maximum eigenvalue statistic is the $5 \%$

critical value. The Johansen maximum eigenvalue test applies to the House Price Index $p_{t}$,

House Rent Index $r_{t}$ and fundamental price-rent ratio $p r_{t}^{f}$. The ADF testing procedure follows

Enders (2010). The Johansen test includes a drift but no linear deterministic in the VECM for the

purpose of enhancing temporal stability (Barkoulas and Baum, 1997, Ahking, 2002). ** and ***

stand for statistical significance at the $5 \%$ and $1 \%$ significance level, respectively. The lower

case letters represent the natural log of the underlying variables. The optimal lag length for the

ADF test and Johansen maximum eigenvalue test are determined by the Schwarz Information

Criterion (SIC). All the three variables are stationary after first difference at the $5 \%$ significance

level. Throughout the paper, the estimation sample ranges from January 1995 to October 2012, except where specifically mentioned. 
Table 2 Maximum Likelihood Estimates of Hyperparameters

\begin{tabular}{|c|c|c|c|c|c|}
\hline \multicolumn{5}{|c|}{$\begin{array}{l}p_{t}=c_{1} p r_{t}^{f}+c_{2} r_{t}+b_{t}+\epsilon_{1} \\
b_{t}=c_{3} b_{t-1}+\epsilon_{2}\end{array}$} & \multirow{2}{*}{$\begin{array}{l}\text { quation (4) } \\
\text { quation (5) } \\
\text { SIC }\end{array}$} \\
\hline$c_{1}$ & $c_{2}$ & $c_{3}$ & $\sigma_{\epsilon_{1}}$ & $\sigma_{\epsilon_{2}}$ & \\
\hline $\begin{array}{c}0.047 * * * \\
(0.015)\end{array}$ & $\begin{array}{c}0.888 * * * \\
(0.083)\end{array}$ & $\begin{array}{c}0.999 * * * \\
(0.004)\end{array}$ & 0.0000027 & 0.0147 & -5.446 \\
\hline \multicolumn{6}{|c|}{ Diagnostic testing for the standardized prediction errors of the State Space Model } \\
\hline \multicolumn{2}{|c|}{$\begin{array}{l}\text { Independence Test } \\
\text { (Box-Ljung statistic) } \\
8.213\end{array}$} & \multicolumn{2}{|c|}{$\begin{array}{c}\text { Homoscedasticity Test } \\
\text { (Breusch-Pagan statistic) } \\
3.031\end{array}$} & \multicolumn{2}{|c|}{$\begin{array}{c}\text { Normality Test } \\
\text { (Jarque-Bera statistic) } \\
1.88\end{array}$} \\
\hline
\end{tabular}

Notes: $p_{t}$ is the house price. $c_{1}, c_{2}$ and $c_{3}$ are the coefficients on the fundamental price-rent ratio $p r_{t}^{f}$, the House Rent Index $r_{t}$ and the deviation from fundamental value $b_{t}$, respectively. $\sigma_{\epsilon_{1}}$ and $\sigma_{\epsilon_{2}}$ are the standard deviations of error terms for the measurement and state equations. See Fig 2 for the calculation of fundamental price-rent ratio at the raw data level. SIC refers to the Schwarz Information Criterion. Standard errors are in parentheses. * and *** represent statistically significance at the $10 \%$ and $1 \%$ significance level, respectively. The lower case letters represent the natural log of the underlying variables. This paper uses the Marquardt algorithm to optimize the likelihood function. Following the testing procedure of Enders (2010), the ADF unit root test statistics for the deviation from fundamental value $b_{t}$ and the differenced deviation from fundamental value $\Delta b_{t}$ are -1.4352 and -4.3914 , respectively. So, the deviation from fundamental value $b_{t}$ is nonstationary in level but stationary after first difference. The null hypothesis for the Box-Ljung test is that the residuals are independent at Q(10). The null hypothesis for the Breusch-Pagan test is that the residuals are homoscedastic. The null hypothesis for the Jarque-Bera test is that the residuals follow a normal distribution. 


\section{Table 3 Johansen Maximum Eigenvalue Cointegration Tests on Bubbles}

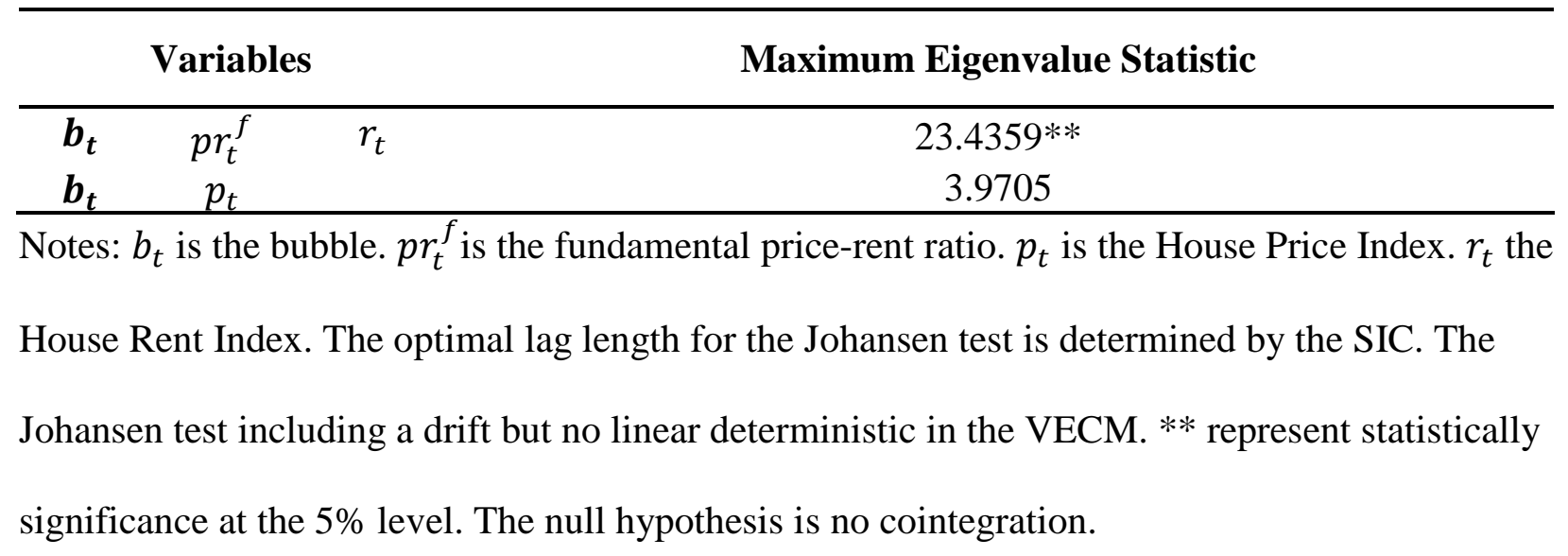


Table 4 Regressions of Bubbles on Fundamentals and Price Dynamics

\begin{tabular}{ccccc}
\hline$\Delta \boldsymbol{b}_{\boldsymbol{t}}=\boldsymbol{\alpha}+\boldsymbol{\beta}_{\mathbf{1}} \Delta \boldsymbol{r}_{\boldsymbol{t}}+\boldsymbol{\beta}_{\mathbf{2}} \Delta \boldsymbol{p} \boldsymbol{r}_{\boldsymbol{t}}^{\boldsymbol{f}}+\boldsymbol{\beta}_{\mathbf{3}} \boldsymbol{c o i n t e q}_{\boldsymbol{t} \mathbf{- 1}}+\boldsymbol{\varepsilon}_{\boldsymbol{t}}$ & & Equation (9) \\
\hline $\boldsymbol{\alpha}$ & $\beta_{1}$ & $\beta_{2}$ & $\beta_{3}$ & $R^{2}$ \\
$0.0036^{* * *}$ & $-0.5477^{*}$ & -0.0113 & $-0.0076^{* *}$ & 0.12 \\
$(0.0011)$ & $(0.3330)$ & $(0.0179)$ & $(0.0034)$ & Equation (10) \\
\hline$\Delta \boldsymbol{b}_{\boldsymbol{t}}=\boldsymbol{\alpha}+\boldsymbol{\beta} \Delta \boldsymbol{p}_{\boldsymbol{t}-\mathbf{1}}+\boldsymbol{\varepsilon}_{\boldsymbol{t}}$ & & & $R^{2}$ \\
$\boldsymbol{\alpha}$ & $\beta$ & & 0.20 \\
0.0009 & $0.3046^{* * *}$ & & & 0.20 \\
$(0.001)$ & $(0.0661)$ & & & \\
\hline
\end{tabular}

Notes: $\Delta b_{t}$ is the change in housing price bubbles, $\Delta r_{t}$ is the change in rent, $\Delta p r_{t}^{f}$ is the change in fundamental price-rent ratio, cointe $q_{t-1}$ is the first lagged cointegration term generated for the bubble $b_{t}$, the fundamental price-rent ratio $\operatorname{pr}_{t}^{f}$ and the House Rent Index $r_{t}$. $\alpha$ is constant, $\beta_{i}$ is the corresponding coefficient. $\Delta p_{t-1}$ is the first lagged changes in house prices. ${ }^{* * *}$ represent significance at $1 \%$ significance level. Standard errors are in parentheses. ${ }^{* *}$ represent significant at 5\% level. * represent significant at $10 \%$ level. 


\section{FIGURES}

Figure 1 House Price Index (Log) vs. House Rent Index (Log)

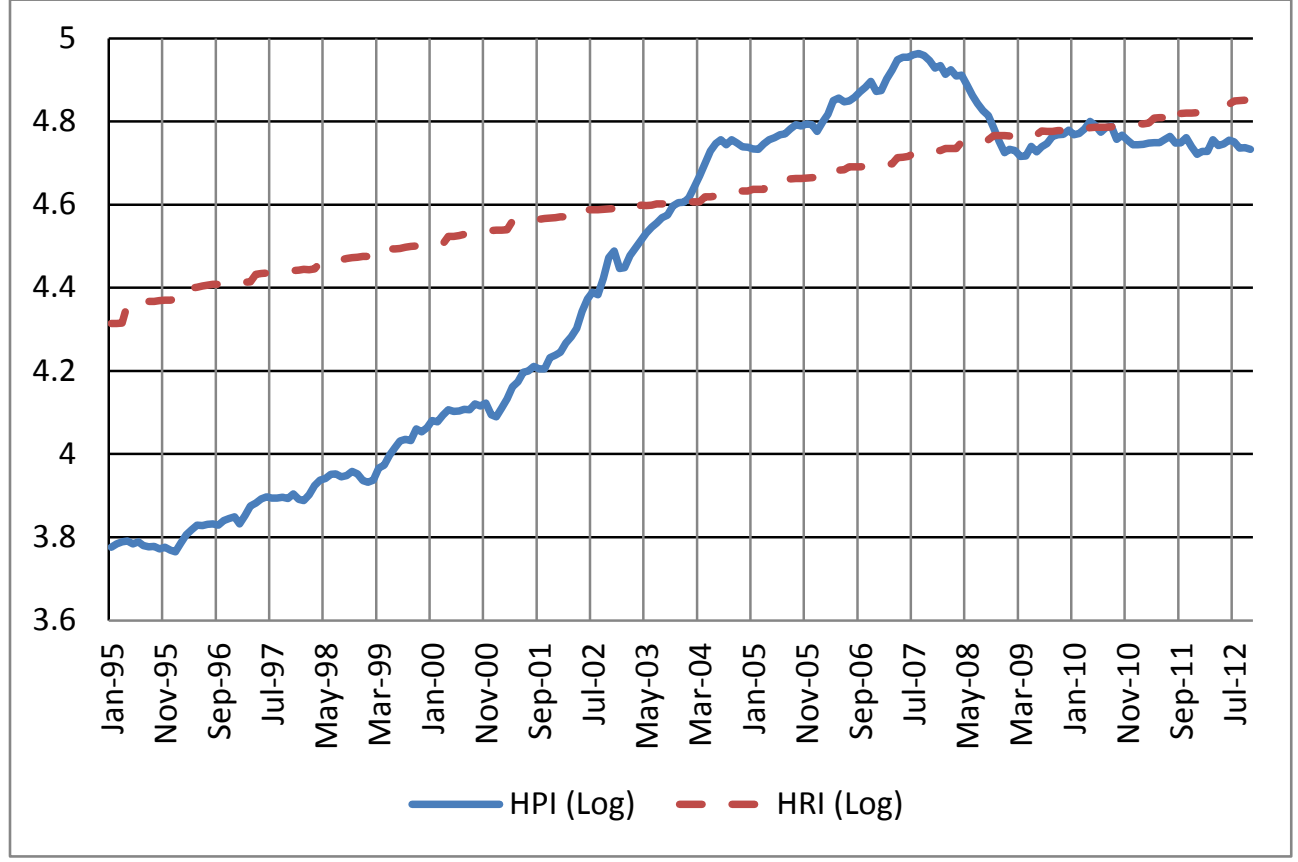

Notes: HPI (Log) and HRI (Log) stand for the Halifax House Price Index and House Rent Index in the natural log scale, respectively. The HRI is derived from the UK Retail Price Index component of rents for housing. This paper sets $H P I=H R I=100$ in November 2003. 
Figure 2 Fundamental Price-Rent Ratio $P_{t}^{f} / R_{t}$

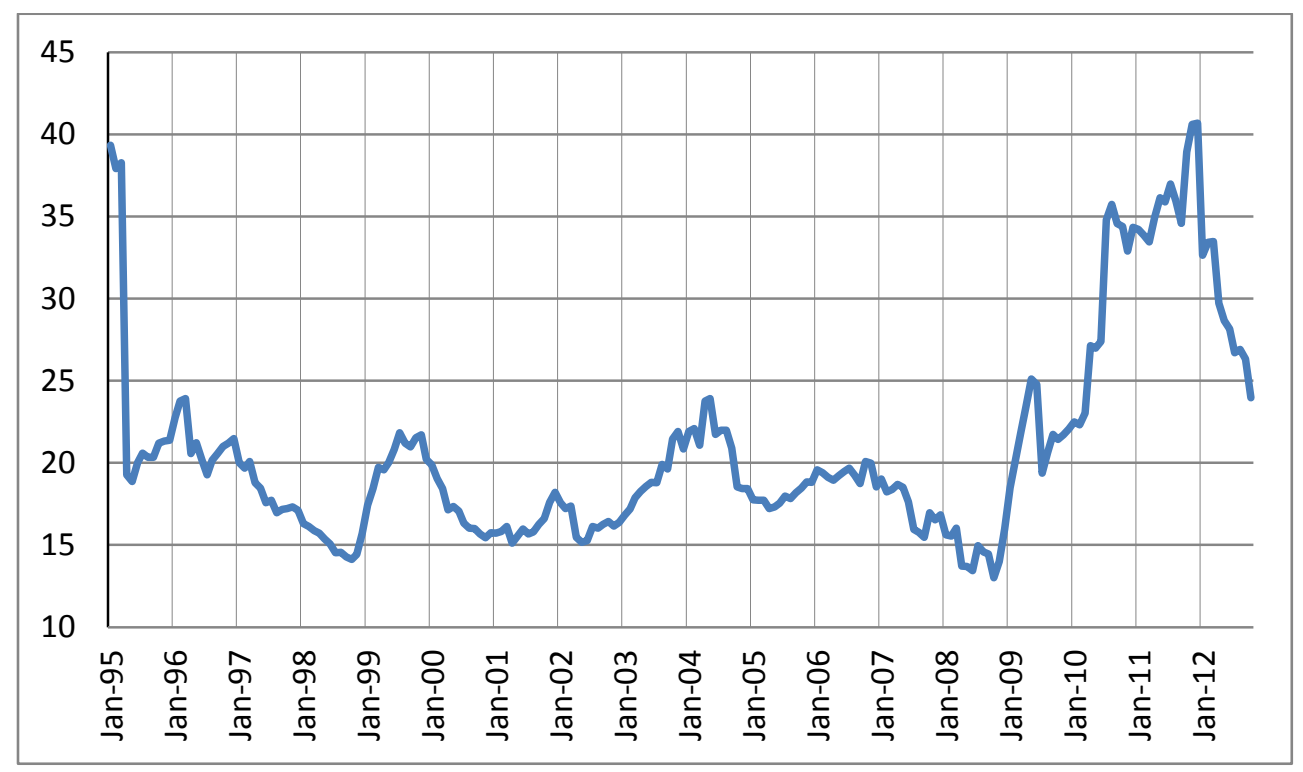

Notes: $P_{t}^{f} / R_{t}=1 / U C_{t}=1 /\left(R_{t}^{m}+P T_{t}+M C_{t}+R P_{t}-M T_{t}\left(R_{t}^{m}+P T_{t}\right)-C G_{t+1}\right) . P_{t}^{f} / R_{t}$ is the Fundamental Price-Rent Ratio. $U C_{t}$ is the User Cost of holding a house per year. $R_{t}^{m}$ is the composite mortgage rate from Bank of England. Property Tax rate $P T_{t}=0$, Maintenance Cost $M C_{t}=2 \%$, Risk Premium for the larger uncertainty of purchasing relative to renting $R P_{t}$ is the difference between the house price appreciation and rent appreciation over next 12 months. $M T_{t}=20 \%$ from April 1994 to March 1995, $M T_{t}=15 \%$ from April 1995 to March 1998, $M T_{t}=10 \%$ from April 1998 to March 2000, and $M T_{t}=0$ thereafter. Expected Capital Gain $C G_{t+1}$ is proxied by the house price appreciation over next 12 months. The expected capital gains from November 2012 to October 2013 are missing, as the paper assumes investors are $e x$ post rational. 
Figure 3 Deviation from Fundamental Value $b_{t}$

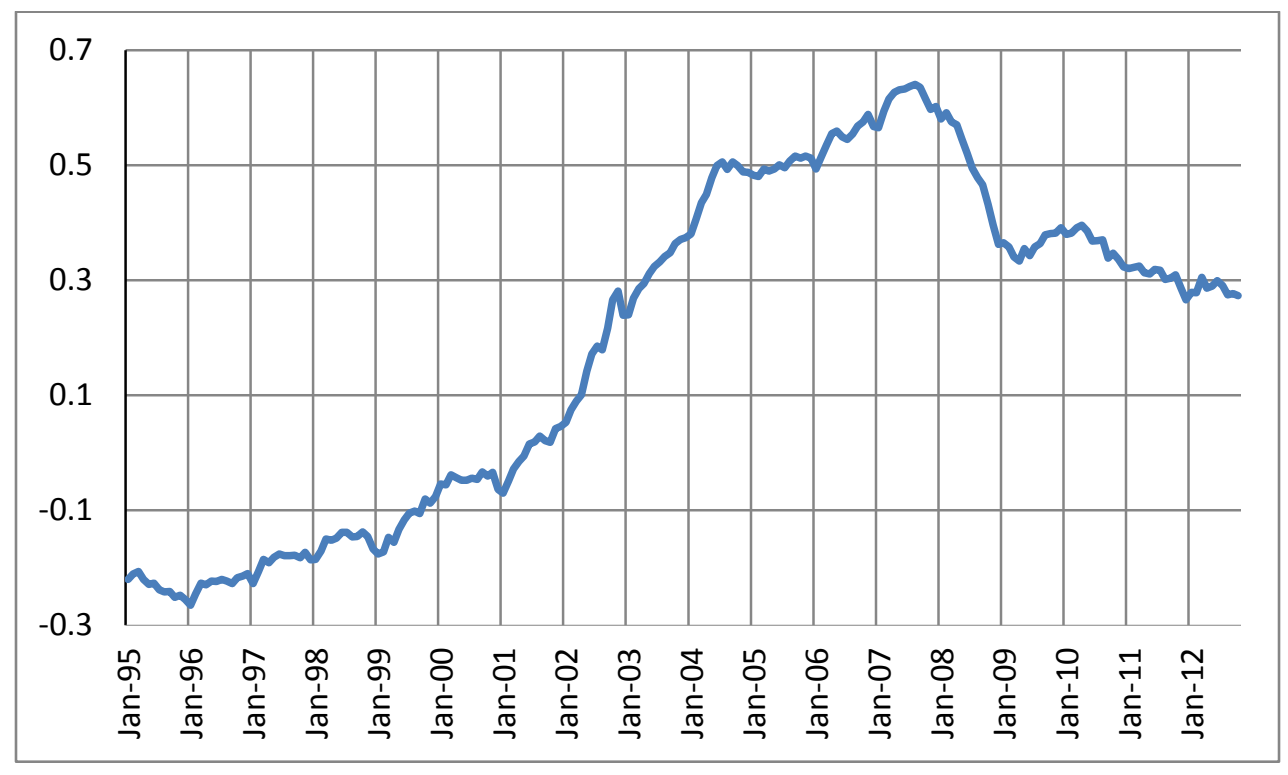

Notes: See Table 2 for the estimation of deviation from fundamental value $b_{t}$ in natural log scale.

When the price-deviation is above 0 this indicates the price is above its fundamental value and vice versa. 
Figure 4 Recursive ADF Tests for Rational Bubbles

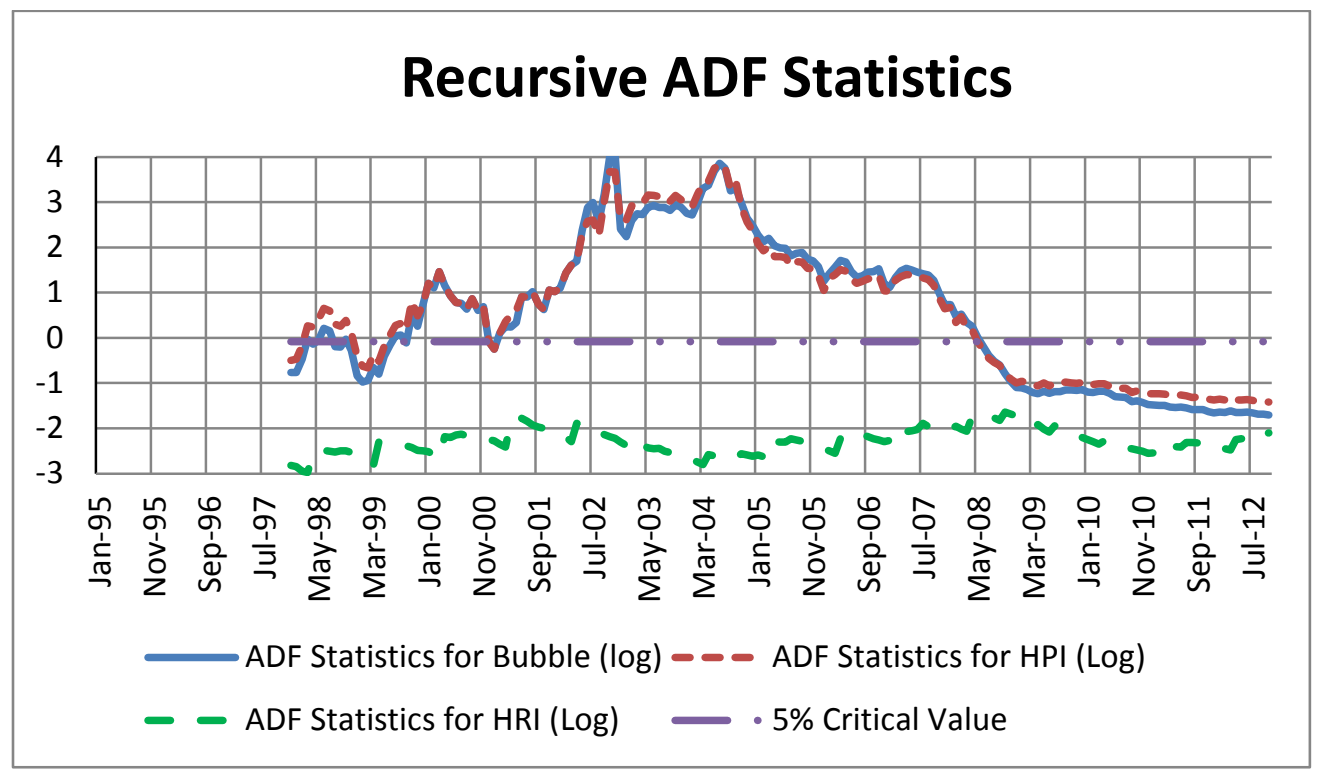

Notes: The figure plots the recursive values of the ADF statistics for the house price bubble $b_{t}$, House Price Index (HPI) $p_{t}$, House Rent Index (HRI) $r_{t}$ against the $5 \%$ critical value for an explosive alternative. The 5\% critical value is from Phillips et al. (2011), which is quite different from the typical Dickey-Fuller 5\% critical value. The first sample period is from January 1995 to December 1997. For each variable, we estimate the following ADF test specification: $x_{t}=\alpha+$ $\delta x_{t-1}+\sum_{i=1}^{I} \beta_{i} \Delta x_{t-i}+\varepsilon_{t}, \quad \varepsilon_{t} \sim N I D\left(0, \sigma^{2}\right)$ as Equation (8). The null hypothesis is $H_{0}: \delta=1$ and the right-tailed alternative hypothesis is $H_{1}: \delta>1$.The optimal lag length is determined using the top-down procedure as in Phillips et al. (2011). 
Figure 5 Recursive Testing for Irrational Bubble Hypothesis

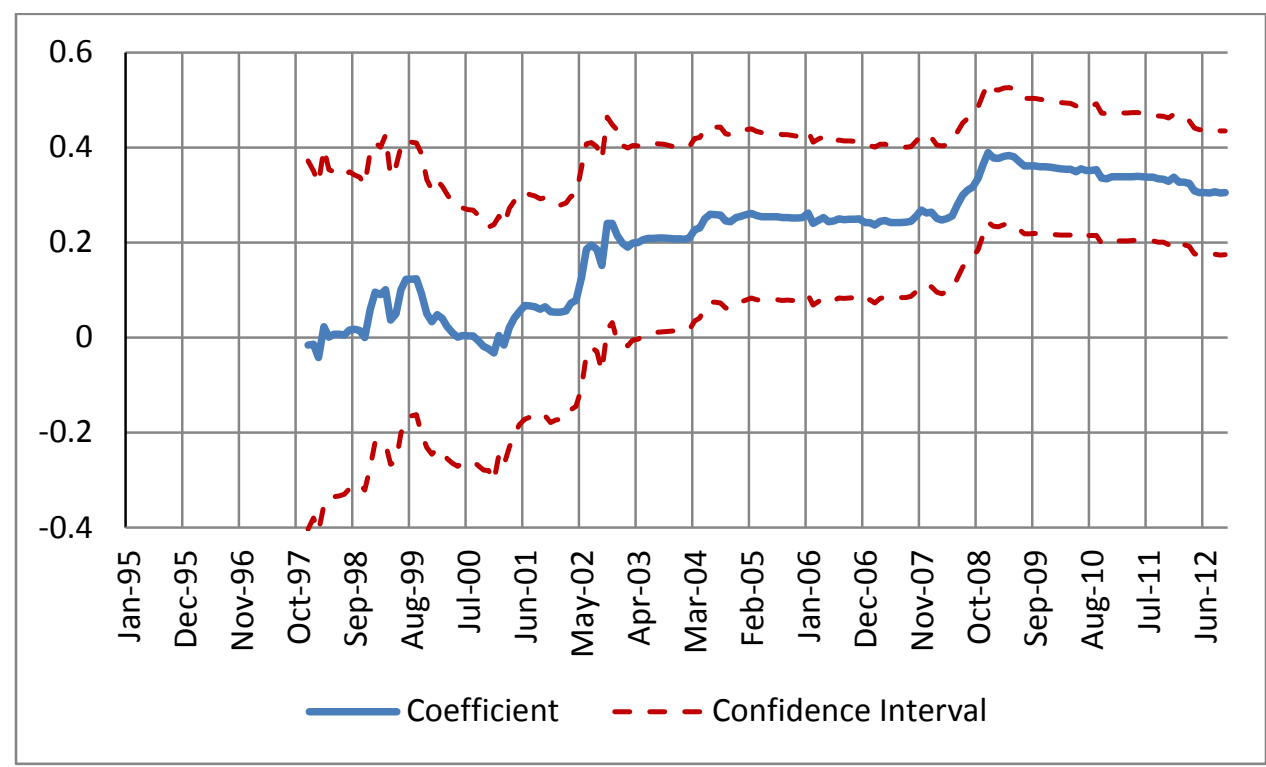

Notes: Recursive regression of equation (10), $\Delta b_{t}=\alpha+\beta \Delta p_{t-1}+\varepsilon_{t}$. The first sample is from January 1995 to December 1997. The solid line represents for the coefficient $\beta$. The dashed line represents the confidence interval for the coefficient at the $5 \%$ significance level. A statistically significant coefficient implies lagged changes in house prices $\Delta p_{t-1}$ would drive the changes in house price bubbles $\Delta b_{t}$, which, in turn, support the irrational expectation hypothesis. 